

\section{INDICE}

EDITORIAL PERSONAL ÁMBITOS

Apresentação do monográfico. Abordagem qualitativa: olhares e práticas transdisciplinares nas ciências antropossociais

Presentation of the monograph. Qualitative approach: transdisciplinary views and practices in anthroposocial sciences

Ronaldo Nunes Linhares, António Pedro Costa

MONOGRAFICOS MONOGRAPHS

Identidades femininas na rede: as crianças falam!

Female identities on line: children can speak

Marta Maria Azevedo Queiroz

$12-31$

Transição de cuidados de enfermagem: ISBAR na promoção da segurança dos

doentes - revisão scoping

Transition of nursing care: ISBAR in promoting patient safety - scoping review

Ana Rita Esteves Figueiredo, Teresa Maria Ferreira dos Santos Potra, Pedro Ricardo Martins Bernardes Lucas

$32-48$

Integración de elementos cualitativos y cuantitativos en metodología observacional

Integration of qualitative and quantitative elements in observational methodology

M. Teresa Anguera, Angel Blanco-Villaseñor, José Luis Losada, Pedro Sánchez-Algarra

49-70

Atos educativos com oficines de ecografias: uma investigação otobiográfica

Educational acts at echographie's cineliers: an otobiographic research

Silas Borges Monteiro, Anaise Avila Severo

Actuación de las políticas: política como texto y política como discurso

Action of policies: policy as text and policy as discourse

Mónica Rocío Barón

88-104 


\section{ÁMBITOS PERSONALES PERSONAL ÁMBITOS}

Un retrato de la cultura local a través del Periodismo cultural. Análisis comparado de Sevilla y Porto Alegre

A portrait of the local culture through cultural Journalism. Comparative analysis of Seville and Porto Alegre

\section{ARTÍCULOS ARTICLES}

Microsociología del profesor universitario

Microsociology of an university professor

Antonio Fernández Vicente

La pobreza y el discurso de los mass media. Un estudio de la prensa local argentina

Poverty and mass media 's discourse. A study of the Argentine local press

María del Rosario Sanchez, Silvia London

La comunicación no verbal en las elecciones andaluzas de 2018. Comparativa de Susana Díaz y Teresa Rodríguez en el debate de RTVE

Non-verbal communication in the Andalusian municipal elections of 2018. Comparison of Susana Díaz and Teresa Rodríguez in the electoral RTVE debate

María Hernández Herrarte, Patricia Zamora-Martínez

El infoentretenimiento en la televisión de pago, Movistar+ y el canal \#0.

El uso transmedia de sus contenidos de humor

Infotainment on pay television, Movistar+ and channel \# 0 . The transmedia use of its humorous content

Metodología y formación docente cuestiones claves para la integración de las TIC en la educación

Methodology and teacher training as a key issue for ICTs integration in Education 


\section{RESEÑAS REVIEWS}

Aquelarre. Mujeres en la cultura de masas

Coven. Women in mass culture

Regla Ismaray Cabreja Piedra

216-220

Transición ecosocial y principios éticos en el periodismo: una guía para la comunicación de nuevas narrativas

The Eco-social transition and ethical principles in journalism: a guide for the communication of new narratives

Amanda Salazar Torres

Narrativas ecofeministas y mapa de transición ecosocial para medios de comunicación Eco-feminist narratives and ecosocial transition map for the media 


\title{
El infoentretenimiento en la televisión de pago, Movistar+ y el canal \#0. El uso transmedia de sus contenidos de humor
}

\author{
Infotainment on pay television, Movistar+ and channel \# 0 . The \\ transmedia use of its humorous content
}

Patricia Gascón-Vera, España, Universidad de Zaragoza, Pedro Cerbuna 12,50009 Zaragoza

patriciagascon@unizar.es | Orcid: https://orcid.org/0000-0002-8516-3225

DOI: https://dx.doi.org/10.12795/Ambitos.2020.i49.11

\begin{abstract}
Resumen 1
El infoentretenimiento como tendencia y los infoshows como género se han consolidado en la televisión desde su privatización. El humor es uno de sus componentes reiterativos, incluso ligado al nacimiento de cadenas de televisión, como en el caso de Cuatro con El Hormiguero y Noche Hache, o en La Sexta con Sé lo que hicisteis y El Intermedio. También el humor es un ingrediente principal de \#0, canal de la plataforma de pago Movistar+ que, en la actualidad, pese a su corta trayectoria, ofrece una decena de nuevos formatos que se iniciaron con la llegada de Andreu Buenafuente. Esta aportación académica recoge los antecedentes del infoentretenimiento en abierto y en los canales de pago como Los Guiñoles de Canal + hasta llegar a la actualidad con distintos formatos humorísticos emitidos en esta plataforma, con los que consigue éxito en las redes sociales, sobre todo, desde La Resistencia o Late Motiv. Para ello, se ha utilizado una combinación metodológica basada en la entrevista en profundidad al responsable de entretenimiento, Eduardo Arroyo, la observación participante en tres formatos y un análisis de contenido sobre el uso de la red social Instagram. Como conclusiones, destaca la gran aglutinación de humoristas y cómicos del país, junto al
\end{abstract}


trabajo de las productoras El Terrat o Globomedia para apostar por el clásico late night o generar nuevas fórmulas como el humor de ficción. Todo en un canal que ha supuesto una evolución de los contenidos, del modelo televisivo del infoentretenimiento en España y su exposición viral.

\begin{abstract}
Infotainment as a trend and infoshows as a genre have been consolidated on television since its privatization. Humor is one of its repetitive components, even linked to the birth of television networks, as in the case of Cuatro with El Hormiguero and Noche Hache, or in La Sexta with Sé lo que hicisteis and El Intermedio. Humor is also a main ingredient of \# 0, the Movistar+ payment platform channel that, despite its short history, currently offers a dozen new formats that began with the arrival of Andreu Buenafuente. This academic contribution collects the background of open infotainment and on paid channels such as Los Guiñoles de Canal + until reaching the present day with different humorous formats broadcast on this platform, with which it achieves success on social networks, especially from La Resistencia or Late Motiv. For this, a methodological combination based on the in-depth interview with the person in charge of entertainment, Eduardo Arroyo, participant observation in three formats and a content analysis on the use of the social network Instagram has been used. As conclusions, the great agglutination of humorists and comedians in the country stands out, along with the work of the producers El Terrat or Globomedia to bet on the classic late night or generate new formulas such as fictional humor. All in a channel that has meant an evolution of the content, of the television model of Infotainment in Spain and its viral exposure.
\end{abstract}

Palabras clave: Infoentretenimiento, televisión, humor, narrativa transmedia, Instagram

Keywords: Infotainment, television, humor, transmedia narrative, Instagram

\title{
1. INTRODUCCIÓN
}

"El infoentretenimiento o infotainment es una tendencia audiovisual que aúna información y entretenimiento en diferentes formatos televisivos", dice Aguilera (2019, p.32). El precursor de este término, Krüger (1988) lo utiliza para referirse a los programas que combinan la información con entretenimiento, siendo una locución que se va a acabar imponiendo para definir el fenómeno no solo en el ámbito internacional, sino también en el español (Berrocal, Redondo, Martín y Campos-Domínguez, 2014, p. 88). Configurando, según Redondo y Campos-Domínguez (2015, p. 74), "una de las tendencias más relevantes dentro del periodismo actual, a escala internacional, especialmente en el medio televisivo". Siguiendo las corrientes de estudio académico sobre el infoentretenimiento de Berrocal et al. (2014) y Ortells (2011), este estudio se encuadraría en la aparición de programas que parodian la actualidad informativa y como género independiente generador de beneficios económicos; ya que aborda la presencia 
del infoentretenimiento en la televisión española, acotando su presencia a la televisión de pago, en el caso de Movistar+ y los contenidos de humor que emiten en su canal \#0, junto con documentales, cine y series de ficción. Y es que como escribían Fernández e Ibáñez (1998, p. 70), "la historia de la televisión es, sobre todo, la historia de su programación", y desde este antecedente de la investigación de la televisión de pago asentaban que, pese la influencia de evolución tecnológica y el aumento de canales no había tantas diferencias en "los contenidos esenciales" y como la "nueva televisión" apostó por programas que se consideraban caducados, películas, series, documentales, adquirieron " un nuevo valor" en la televisión multicanal".

Como apuntan Medina, Herrero y Etayo (2015, p. 253), en su estudio sobre las estrategias de la televisión de pago en televisión, "el panorama del mercado audiovisual ha cambiado dramáticamente en los últimos treinta años, y más aún desde la implementación de la televisión digital terrestre en toda Europa". La llegada de nuevos canales de TDT, las innovaciones tecnológicas, la entrada de los operadores móviles y el reciente éxito de nuevos proveedores de contenido audiovisual desde plataformas de consumo online han creado nuevos servicios de pago junto con la oferta de televisión, ya no tan tradicional. Como presagiaban, "la mayoría de los contenidos populares gratuitos, especialmente los deportes y las películas, se convertirán en contenido premium, por lo que la televisión de pago crecerá en los próximos años" (p. 266).

Actualmente, Movistar+, plataforma por suscripción propiedad de Telefónica, es la que dispone de más abonados a la televisión de pago cuatro millones, sobre un total de, 6.780.268. Además, de los 553 millones de euros de ingresos, 430 corresponden a esta plataforma, según la Comisión Nacional de los Mercados y la Competencia. En este escenario, otras plataformas nacionales de contenidos son Atresplayer; donde se pueden visionar los contenidos de este grupo de comunicación y marcas como Flooxer, y Mitele, plataforma de Mediaset España y que permite visionar televisión a la carta y en directo. Ambas disponen de contenidos en abierto y bajo suscripción. Por su parte, TVE a finales de 2017 lanzó Playz, la plataforma digital de RTVE con webseries, programas, podcasts o documentales, además de otras como te Filmin o Filmotech.

Tal y como coteja también la CNMC, un tercio de los hogares españoles utilizaron una plataforma de pago para consumir contenidos audiovisuales online, con los siguientes porcentajes: YouTube con un 52\%, seguida por Atresplayer (35\%), RTVE.es (31\%), Mitele $(29 \%)$ y Movistar+ $(25 \%)$. Cifras a las que hay que sumar otros consumos de vídeos virales, series y películas a través de las 'superplataformas' de streaming mundiales. Como las internacionales HBO y Netflix, que dispone de más de 151 millones de suscriptores en más de 190 países, según su servicio web; además de otras como Amazon Prime Video. Una lista a la que se han añadido las plataformas de otras tres grandes compañías: Disney+, AppleTV + y HBOMax (Elidrissi, 2019). Para Medina, Herrero y Portilla (2019, p. 1.762) los límites entre canales, operadores y servicios over- 
the-top (OTT) son difíciles de señalar, no obstante, determinan que para la audiencia la importancia radica en el contenido, siendo "el núcleo del servicio de televisión".

Un universo de contenidos desde el que afronta el reto de fidelización de los usuarios. Sobre Movistar+, Torres $(2019$, p. 735$)$, determina que "el grueso de la oferta se basa en series de ficción, pero también las hay exclusivas de cine y en la mayoría de ellas se van incluyendo otros formatos de entretenimiento (...)", al mismo tiempo que exploran "las nuevas posibilidades expresivas de las técnicas transmedia". Para Evans (2011, p. 19), el concepto transmedia storytelling es un elemento central que ayuda a comprender cómo las nuevas tecnologías y medios emergentes están generando nuevas fórmulas para narrar el contenido y para la participación de la audiencia. Son aquellos contenidos que se crean con una narrativa enfocada a las redes sociales y a la viralidad, en algunas ocasiones como soporte, pero, sobre todo, como creación independiente. Lamelo (2016) expone que la televisión se une a nuevas narrativas transmedia, siendo el soporte con mayores posibilidades. Los espectadores han cambiado sus consumos y las redes sociales son amplificadores de los contenidos, y, en definitiva, se ha cambiado el modo como se cuentan las historias (Scolari, 2013). Una nueva forma de comunicar (Jenkins, 2015), ya que con esta narrativa se llega a diferentes segmentos de la audiencia, desde creaciones diferenciales en las que el usuario puede decidir su grado de inmersión. Creaciones exprofeso o contenidos que generan nuevos consumos, y es que las nuevas técnicas como las historias de Instagram generan popularidad, según Amâncio (2017, p. 32) y se fundamenta en el paradigma narrativo de Fisher (1984): "Los seres humanos somos narradores naturales”. Como asegura Balboa (2018, p. 24):

La llegada del canal \#0 en febrero de 2016 supuso el comienzo de una nueva época para el humor en España. Y es que, a través de un uso efectivo de redes sociales y plataformas de vídeo online, ha conseguido apropiarse de un target televisivo joven y activo en redes; hecho que ha propiciado el aumento de la viralización de sus contenidos.

Así pues, la justificación de este estudio es su referencia a un importante ámbito de interés, el de la historia de televisión española reciente, dentro, a su vez, del campo de la programación y sus estrategias. Para ello, se analiza la historia del infoentretenimiento, la llegada a los canales generalistas y de pago, la expansión de las plataformas y el nacimiento del canal de estudio. Una aportación novedosa cuyo objetivo principal es conocer cómo es la programación de \#0 dedicada al infoentretenimiento, lo que se completa con el análisis de una de las estrategias actuales de comunicación, la narrativa transmedia, para conocer cómo estos formatos utilizan la red social Instagram para acercarse a su público. Gracias a la entrevista en profundidad y al análisis de contenido se aporta una aproximación al infoentretenimiento en los inicios de 2020. 


\section{METODOLOGÍA}

La $V$ edición del Congreso de la Comediaz derivó en una entrevista en profundidad al Jefe de Contenidos de Entretenimiento de Movistar+, Eduardo Arroyo quien ha participado como responsable en proyectos como Caiga Quien Caiga, UHF, Noche Hache. Un recurso metodológico que, al igual que el caso de Fernández Jiménez (2018, p. 295), se considera "fundamental", ya que se analiza "un objeto de estudio vivo del cual sus protagonistas pueden dar ideas clave para un mejor entendimiento". Esta aportación se basa en la información inédita junto con un análisis descriptivo e histórico de formatos que han formado parte de la historia televisiva ligada al infoentretenimiento, mientras que, de forma complementaria, se ha asistido como observadora participante pasiva en la grabación de tres de los formatos de \#0: LocoMundo, Late Motiv y Dar Cera Pulir \#0. De forma adicional, este método permite hacer observaciones sobre el comportamiento de los miembros (Gibbs, 2015, p. 193), con el objetivo de captar la realidad, dicen por su parte, Casetti, y Di Chio (1999, p. 223). Así estas técnicas se implementan, al igual que Gascón-Vera y Marta-Lazo (2019, p. 76), con el objetivo de completar resultados, puesto que cumplen "el doble objetivo de conocer de primera mano los procesos de ejecución de esta producción audiovisual y ofrecer una información novedosa, directa y completa". De este modo, se trata de un prisma novedoso con el que abordar la llegada de las plataformas de contenido, concretamente Movistar+, para conocer el uso de los contenidos de humor de \#0 desde su nacimiento, así como la importancia en su programación.

Al mismo tiempo, se efectúa un análisis de la estrategia transmedia que realizan tres formatos de \#0: La Resistencia, Late Motiv y Las que Faltaban de la red social Instagram. Con el objetivo de ofrecer una aproximación de cómo llegan a su público objetivo y cómo realizan la exposición de los contenidos. Para ello, se ha efectuado un análisis de contenido sobre sus publicaciones e historias (Stories), durante cinco días de programación, concretamente del 13 al 17 de mayo de 2019, para dar respuesta a todas las emisiones semanales -ya que los primeros son diarios y el último no-, y a mitad de temporada para estabilizar los resultados. La hoja de codificación diseñada ha contabilizado la narrativa utilizada, según seis recursos o medios para contar sus historias basados en los que efectúa Amâncio (2017): Fotografía, video, promoción, retweets del público, capturas de otros contenidos o redes sociales, memes de propia creación o externos y publicidad. 


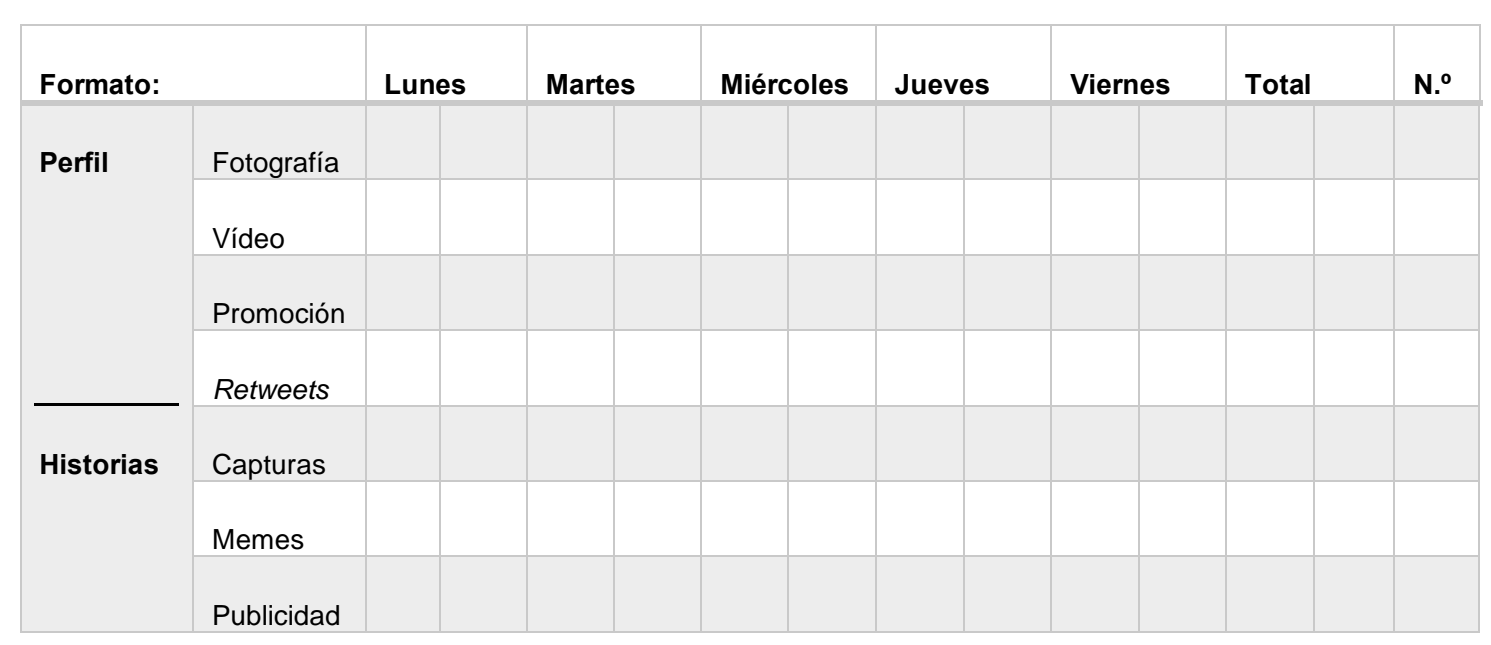

Figura 1: Ficha de codificación: análisis de contenido en la red Instagram Fuente: Elaboración propia

\section{ESTADO DE LA CUESTIÓN}

Salgado (2010, p.61) se refiere a los principales investigadores sobre el infoentretenimiento como González-Requena (1989), quien avisaba de la llegada del espectáculo informativo, así como la determinación de infoshow del que se remarca su preponderancia en las parrillas de televisión desde múltiples subgéneros para buscar la audiencia (Prado et al. 1999 y Prado 2003). Como continúa Salgado (pp. 62 y 63), y apoyan autores como Aguilera (2019, p. 33) y Arroyo (2008, pp. 173-177), se entiende infoentretenimiento como la gran tendencia y los infoshow como aquellos formatos en los que se plasma. Una taxonomía desde la que se abordan estudios como el de GarcíaAvilés quien aporta las denominaciones pseudoperiodismo de humor (1999) y periodismo de entretenimiento (2004) al igual que Valhondo sobre la infosátira (2007) y la sátira televisiva (2011). Se parte, asimismo, de las contribuciones de Ortells (2009, 2011) y de Berrocal, Redondo y Campos-Domínguez (2012), con su análisis del infoentretenimiento en Internet y también de los canales generalistas de la TDT (2014) donde trabajan formatos representativos, recuerdan los orígenes del infoentretenimiento, así como sus características técnicas. También Martín y Berrocal (2017) analizan los pioneros del infoentretenimiento político en la televisión española. Gordillo, además de trabajar la taxonomía (2009), analiza los orígenes del infoentretenimiento desde la radio y los precursores televisivos (2010). En este sentido Méndez (2004) examina el humor televisivo en los noventa, que se suma a lo indicado en el libro colectivo sobre el infoentretenimiento de Ferré (2013). Juntamente con publicaciones como la tesis de Carpio (2008) sobre Las Noticias del Guiñol o el estudio de formatos recientes Gascón-Vera, (2016) y Balboa (2018). Todo ello, complementado con precedentes internacionales (Thussu, 2007; Bordieu, 1997 o Brants, 1998). 


\section{DESAROLLO HISTÓRICO DEL INFOENTRETENIMIENTO TELEVISIVO}

García-Avilés (2007, p.50) destaca las palabras de Winch (1997) quien asegura que "resulta evidente que la información televisiva ha desarrollado un componente de entretenimiento desde sus orígenes". Una hibridación, un género independiente ligado a los orígenes de la televisión que como señala Antona (2017, p.31), independientemente de su propiedad, ya sea pública o privada "el entretenimiento constituye una pieza fundamental en la oferta de las televisiones generalistas" y señala que no es solo un rasgo contemporáneo, ya que "la televisión nació con esta vocación y los espectadores la recibieron como tal". Siendo Licencia para reír en 1960, Gran Parada (1963-1964) o Cita con Tony Leblanc (1969), algunos de los primeros formatos que emitió la televisión pública española en su etapa de monopolio. Después, el humor se constituyó como una parte de concursos, Un, dos, tres responda otra vez (19722004), o de programas de variedades, Noche de fiesta (1999-2004).

En estos foros el humor televisivo comenzó a fraguarse con figuras como Gila, Arévalo, Eugenio y el dúo Tip y Coll. Como apunta Casado (2017) se trató de una de las parejas más reseñables realizando "un humor surrealista y sarcástico sobre problemas nacionales o internacionales de la actualidad" gracias a expresiones como "la semana que viene hablaremos del Gobierno". Su humor, según Méndez (2004, p.161), se apartó de los modelos del momento y fueron pioneros en "hacer humor sobre el género noticia" que exportaron, como reseña Sangro (2008, p. 64), en el programa Todo es posible en Domingo (TVE, 1974), primero y con la llegada de su formato propio Lo de Tip y Coll, después. Asimismo, siguieron espacios de variedades, Pero ¿esto qué es? (TVE, 19891991) y Como Pedro por su casa (TVE, 1985) en el que Pedro Ruiz realizaba entrevistas, protagonizaba sketches junto con chistes, parodias, imitaciones y sátira política (Fernández Jiménez, 2018, p. 300); hasta que a mediados de los noventa el humor televisivo se hizo autónomo (Méndez, 2004, p. 162).

\subsection{La privatización de la televisión, inicio de la era del infoentretenimiento}

La mayoría de las investigaciones fijan el inicio de la hibridación entre información y entretenimiento entre finales de los 80 , originariamente en los canales locales de Estados Unidos, y principios de los años 90, en occidente, (Berrocal et al., 2014, p. 88), como resultado de la llegada de la televisión privada. Un hecho que aumentó la competencia televisiva y marcó la necesidad de generar estrategias y nuevos contenidos para "para atraer a una audiencia masiva" y, más diversificada, motivos que señalan Berrocal et al. (2012, p. 66).

Según Valhondo (2007, p. 63), este tipo formatos aparecieron en las parrillas televisivas a mediados de los años 90, fechas desde la que aumentó "su colonización en las rejillas televisivas". De esta forma, el infoentretenimiento, proceso global que nace a mediados de los 80 en EE. UU., se inicia en España la década de los noventa debido al proceso 
de privatización, dando lugar a una tendencia en la programación, como resultado de la lucha por las audiencias. Así, debido al aumento de la competencia, con la llegada de las cadenas privadas, Antena 3 y Telecinco, se inicia un nuevo escenario con propuestas como Vip o Tutti Fruti, ambas en Telecinco, configurándose como el inicio de la tendencia del entretenimiento, humor, actualidad. Según Contreras y Palacio (2001, p. 155): "Con Telecinco, en España aprendimos a ver y a hacer televisión de entretenimiento".

Tras estos primeros exponentes, llegan, como determinan Berrocal et al. (2014, p. 92), los programas pioneros del infoentretenimiento en España, que son programas de humor Los Guiñoles de Canal+ (Canal+, 1995-2008; Cuatro, 2005-2008) y Caiga quien Caiga (Telecinco, 1996-2002/2005-2008; La Sexta: 2008; Cuatro, 2010) o El Informal (1998-2002), que añade como génesis de los formatos de periodismo satírico Salgado (2010, p. 64).

También Gordillo (2010) y Méndez (2004) se refieren a la emisión de estos formatos en los 2000, aunque previamente también habían aparecido los primeros late nights, un género que, como recuerda Salgado (2006, p. 111), llegó a España en 1995 de la mano de Pepe Navarro, con Esta noche cruzamos el Mississippi (Telecinco) y que se readaptaría en Antena 3 como La sonrisa del pelícano (1997). Además de otros como La azotea de Wyoming (TVE, 2005), Crónicas Marcianas (Telecinco, 1997-2005) de Javier Sardá o Noche Hache (Cuatro, 2005-2008). Éste último junto con la llegada de dos nuevas cadenas, Cuatro en noviembre de 2005, que "aportó aire fresco al panorama humorístico nacional lanzado formatos de éxito", según Buenafuente (2011, p. 59)" y La Sexta en marzo de 2006, cuya parrilla estaba compuesta por humor, entretenimiento y deporte. Desde 2006, (Gascón-Vera, 2016) El Hormiguero y El Intermedio se mantienen en antena y se unen a otros intentos efímeros como Dani \& Flo (Cuatro, 2017-2018), Lo Siguiente (La 1, 2018-2019) o recientes como Todo es mentira (Cuatro, 2019.-).

\subsection{El infoentretenimiento en la televisión de pago}

Por su parte, la televisión de pago en España llegó juntamente con las cadenas privadas en 1990, desde Canal+, el pionero en la televisión de pago en España, hasta el año 2016 cuando se trasformó en \#0, canal de la plataforma Movistar+. En sus comienzos emitía en directo seis horas al día formatos como el magacín Lo + Plus, donde se inició como sección el informativo satírico Las Noticias del guiñol y, después, como formato se emitió desde 1995, tras el informativo de la noche, aunque de 2006 a 2008 se emitió en Cuatro, como sección, del formato Noche Hache. Según el anuario GECA (1999, p. 162), era un espacio protagonizado por un amplio plantel de muñecos que retrataba desde la sátira los asuntos más destacados de la actualidad política, social o deportiva. Dichos formatos de infoentretenimiento se unían a estrenos de cine y retransmisiones de fútbol, ambas para abonados, hasta que su historia, ligada a los cambios del mercado 
audiovisual español, viró en 1997 cuando se renovó y amplió con su emisión por satélite denominándose Canal Satélite Digital, propiedad de Prisa TV. Años después, en 2003, se fusionó con Vía Digital, perteneciente a Telefónica, dando lugar a Digital+. Posteriormente, desde noviembre de 2005, su señal analógica paso a ser la cadena Cuatro, y estuvo solo disponible desde la plataforma de satélite hasta ser \#0. También en este escenario, en marzo de 1999, llegó a España el canal de suscripción de origen estadounidense Paramount Comedy, actualmente Comedy Central, que ha emitido formatos como La hora chanante, late night shows y espacios de stand-up como Nuevos cómicos o Central de cómicos. Y es que como apunta sobre este canal Salgado (2006, p. 115) "en España hay canales autonómicos, temáticos y locales que cuentan con buenos programas de humor".

Posteriormente, \#0 inicia su emisión a principios de 2016, sustituyendo a Canal+, desde su sede en Tres Cantos en Madrid. Reconvertido, pero manteniendo la esencia, recuperó desde sus inicios formatos anteriores como llustres Ignorantes, un formato longevo que comenzó a emitirse en 2008 en Canal+ y en el que rostros como Javier Coronas y Javier Cansado realizan un debate humorístico. Documentales, ficción y cine junto con el contenido humorístico seña de identidad que se inició de la mano de fichajes como Andreu Buenafuente (Viciosa, 2016) y su Late Motiv, La Resistencia, Locomundo, Cero en Historia, los más recientes como El cielo puede esperar o Dar Cera, Pulir \#0, además de los ya cancelados Las que Faltaban o WifiLeaks.

\section{RESULTADOS}

\subsection{Apuesta por el humor en \#0, entrevista en profundidad}

Eduardo Arroyo, director de entretenimiento de \#0, expone que los inicios del canal pasaron por la decisión de recuperar el late night, que estaba desaparecido del panorama televisivo. Al mismo tiempo, se decide continuar con llustres ignorantes, un programa emblemático de Canal+ y se testan dos otros formatos de entretenimiento como Web Therapy de Eva Hache, además del concurso Spoiler y el talent show ACapelA. Y es que como detalla Arroyo existen dos ramas para el entretenimiento en este canal de pago: el entretenimiento de humor y el factual, con formatos como Fama. "Poco a poco vamos viendo que el programa más visto con diferencia es llustres Ignorantes y Andreu Buenafuente se convierte en la cara de la cadena", puesto que, como explica, según estudios cualitativos de la entidad, el público asocia el canal a Andreu Buenafuente, a pesar de contar con otros rostros populares como Raquel Sánchez-Silva, Javier Coronas, Jon Sistiaga o Iñaki Gabilondo.

"Vemos que los programas de humor funcionan y que la gente demanda humor", reconoce el coordinador del humor de \#0 y con esta premisa se van asentando los datos, los rostros y el humor comienza a crecer al igual que lo hace David Broncano. Quien emprende su salto en solitario desde Late Motiv con LocoMundo, formato que 
presentará en sus primeras temporadas. "LocoMundo es la niña de mis ojos porque es el programa que más me recuerda a lo que he hecho toda mi vida, con un guion más sólido trabajado, y que mira mucho a John Oliver 3", comenta. En este proceso se consolida LocoMundo, a Broncano "se le empieza a quedar pequeño" y nace La Resistencia, uno de los formatos de humor con mayor éxito entre el público. De este modo, se decide que LocoMundo es un formato potente que puede estar en manos de otra persona y Quequé se convierte en su nuevo presentador, y "Ilega hasta funcionar mejor", según Arroyo. "El humor chuta", apunta, y da paso a la incorporación de Cero en historia o Capitulo Cero, que permite a Joaquín Reyes y a Ernesto Sevilla hacer ficción unida al humor. Por su parte, en la temporada 2018-2019 se estrenó Las que Faltaban, humor femenino presentado por Thais Villas y que no superó una segunda temporada y otras ofertas recientes como El Cielo puede esperar producido por la nueva productora de José Miguel Contreras, Lacoproductora, y Dar Cera, Pulir \#0, de Globomedia.
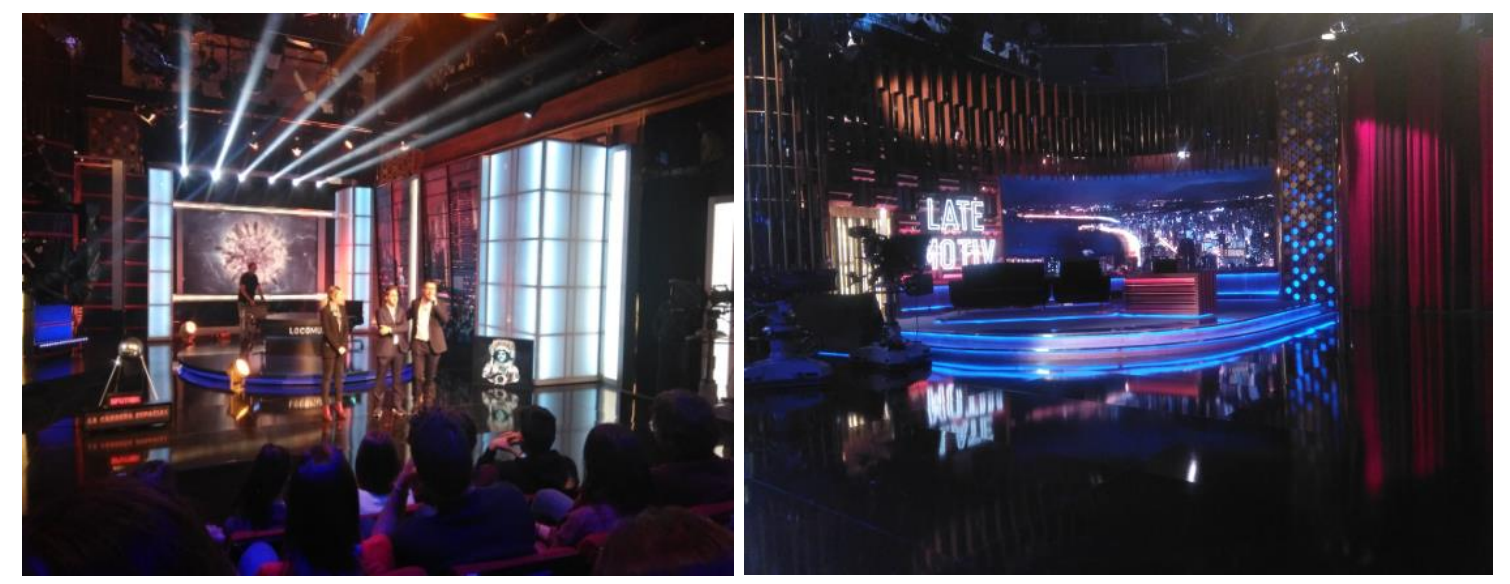

Figura 2. Fotografías de la grabación de los programas LocoMundo (94): Carrera Espacial y Late Motiv 659

Fuente: Elaboración propia

Se trata pues de "un crecimiento exponencial," como afirma Arroyo, ya que se ha pasado de los tres o cuatro formatos iniciales a una decena, a los que hay que sumar, además, otros formatos de entretenimiento. En relación con las cancelaciones del magacine Likes o de WikiLeaks, Arroyo estima que el access prime time no es una franja horaria en la, desde el canal de pago, hayan conseguido éxito. Como explica, el consumo de pago y de productos bajo demanda está condicionado, en primer lugar, a la hora de emisión, si los espectadores lo ven en línea y, por otro lado, al visionado posterior VOD, el cual no está ligado, precisamente, a aquellos contenidos con una gran caducidad por los temas que manejan estos tipos de programas. "La gente puede seguir consumiendo series, ficción, Late Motiv o incluso LocoMundo puesto que trata asuntos como la energía nuclear, pero es prácticamente nulo que un espectador pueda estar interesado en escuchar un magazín de hace cuatro meses o un año atrás donde las noticias están 
caducas y descontextualizadas", afirma. De esta forma, la experiencia, los formatos históricos, horarios y contenidos generales ligados a la actualidad, pero pensados para un consumo bajo demanda o atemporal dan como resultado una serie de títulos que generan el éxito.

El humor funciona de la mano de los rostros conocidos, de los nombres propios de la comedia, 'la flor y nata' del mundo del entretenimiento televisivo. "Nos damos cuenta de que el humor funciona y en la escudería de Movistar+ está casi todo el mundo y cada vez vamos incorporando más", resume Arroyo y añade que "no es fácil lidiar con todos, pero es divertido". "Saben en qué cadena estamos y que son programas de pago en los que no tienes la repercusión de otros canales", y aunque el fenómeno más claro actualmente, como señala, es el de David Broncano, destaca su capacidad para gestionar el éxito.

Para Arroyo, en la actualidad, se ha "descuidado el humor" y en casos como el de Antena 3 han apostado por el entretenimiento familiar desde formatos como Ahora Caigo (2001.-) de Arturo Vals, el programa de Silvia Abril Juego de juegos (2019) o Tu Cara me suena (2001.-) presentado por Manel Fuentes. Entretenimiento frente al humor. "Quizás lo más cercano al humor es Me Resbala (Antena 3, 2013-2017), pero es un humor más loco más cercano al Gran Prix (TVE, 1995-2009) o Qué apostamos (TVE, 1993-2008), un concurso más que programas como El Club de la comedia (emitido por todas las cadenas generalistas) o Noche Hache (Cuatro, 2005-2008)", enfatiza. Una realidad que este creador televisivo hila con la situación actual del humor: "Como estamos viviendo estos días -en el momento de la entrevista se eliminó un monólogo de Iggi Urbin 4 de la plataforma- el humor es cada vez más delicado y qué mejor manera de quitarte problemas que prescindiendo de él".

De este modo, mientras el humor va quedando en menor medida en el contenido generalista, en la temporada 2018-2019 la programación ligada al humor está protagonizada por dos bastiones El Intermedio o El Hormiguero. Por su parte, en la estructura la parrilla de \#0, según argumenta Arroyo, este contenido de humor "no se pisa entre sí". Cada uno de los espacios ocupa un lugar y genera el interés del público. También explica que la única duda que han tenido en cuanto a programación fue la concatenación de los dos late night Late Motiv y La Resistencia. Sin embargo, en su programación uno tras otro, "conviven de maravilla, porque son dos enfoques completamente distintos". "Del clásico Andreu al giro totalmente nuevo al late que ha dado Broncano. De los colaboradores clásicos como Berto y los disparates de Jorge Ponce hay un mundo, aunque estas viendo un mismo formato estás viendo dos programas distintos", detalla.

En esta cambiante televisión, el humor los formatos se han consolidado, pero es necesario renovarse. "Hemos incorporado programas distintos como Cero en historia, 
algo más cerca de la ficción, como Capítulo Cero y estamos buscando nuevos territorios dentro de la comedia como, por ejemplo, la cantidad de gente que quiere recuperar $E l$ Club de la comedia". "No paramos, porque además sabemos que funciona y tampoco tenemos la presión del dato de audiencia, podemos permitirnos trabajar con más colchón". Como determina Arroyo, la libertad creativa no sujeta a una cifra de audiencia como meta última libera los equipos y la fortaleza de los programas, siendo ésta una de las diferencias fundamentales contra las grandes cadenas de comunicación donde la alta rentabilidad real, casi desde el primer día, frena ideas y obstaculiza que se puedan estabilizar los proyectos audiovisuales.

Una clara línea editorial, productoras ligadas al humor, formatos probados junto con nuevos... ¿cómo se logra una la fórmula del humor partiendo de cero? Para Arroyo, se alcanza fundamentalmente apostando por él, "es tan sencillo como que lo que funciona vamos a por ello", responde. Por otro lado, estima que algunos de los programas de Movistar+ como Radio Gaga que está dando mucho prestigio a la cadena o el producido por Jon Sistiaga deberían estar en la televisión pública. "Se ha indagado en un formato belga como Gaga que hace la productora Magnolia al igual que Capítulo 0, apostamos, vemos que funciona y tiramos para adelante y con el humor ha pasado lo mismo. Si funciona un late y crece un colaborador se hace otro late. Que Joaquín y Ernesto son pilares de la comedia pues les damos una serie, si hay mujeres en el humor por qué no apostar por ello", concluye. En definitiva, Arroyo traslada una apuesta decidida y constante por el humor que ha generado toda una serie de formatos que forman parte de un nuevo capítulo y escenario televisivo en la historia presente.

\subsection{El uso de las narrativas transmedia de \#0 en la red social Instagram}

\section{Tabla 1}

Cifras de las cuentas de Instagram, comparativa anual y de otros formatos

\begin{tabular}{lcccc}
\hline \hline & & Publicaciones & Seguidores & Seguidos \\
\hline \hline \multirow{2}{*}{ La Resistencia } & 2020 & 2,655 & $\mathbf{1 . 2 5 9 . 0 6 2}$ & 1 \\
& 2019 & 1.088 & 693.000 & 1 \\
\hline \multirow{2}{*}{ Late Motiv } & 2020 & 2.897 & 253.266 & 292 \\
& 2019 & 1.895 & 156.000 & 201 \\
\hline \multirow{2}{*}{ Las que faltaban } & 2020 & 441 & 55.895 & 16 \\
& 2019 & 152 & 5.120 & 107 \\
\hline El Hormiguero & 2020 & 4.431 & $\mathbf{1 . 1 9 2 . 2 7 8}$ & 326 \\
\hline
\end{tabular}




\begin{tabular}{lcccc}
\hline El Intermedio & 2020 & 278 & 116.000 & 8 \\
\hline Todo es mentira & 2020 & 269 & 18.774 & 176
\end{tabular}

Fuente: Elaboración propia

Sobre los tres perfiles que componen la muestra analizada, cabe señalar que su cifra de seguidores es irregular5, y que las cuentas de los programas disponen de un grafismo unitario. Además, se comprueba que, de forma prospectiva, todos han sumado audiencia y contenidos. Con especial mención a la cuenta de La Resistencia que, en menos de un año, ha incrementado sus seguidores hasta superar a El Hormiguero.

Tras la comparativa, en el análisis de contenido transmedia se ha constatado un importante volumen de contenidos en los tres formatos, que comparten estrategias similares, al mismo tiempo que características propias. Como resultados generales, el uso de historias triplica al de publicaciones en datos conjuntos y por espacios; La Resistencia supera las cien historias en cinco días superando por el doble al resto. También el volumen de publicaciones está relacionado con el público objetivo, ya que en La Resistencia y Las que Faltaban, espacios dirigidos a un público más joven, se comprueba un mayor uso de las historias de Instagram frente a las publicaciones, aunque siempre se actualizan a diario.

Tabla 2

Número de historias, publicaciones en el perfil y su cómputo total

\begin{tabular}{llllllll}
\hline \multirow{2}{*}{ La Resistencia } & Historias & 5 & 32 & 14 & 29 & 26 & 106 \\
& Perfil & 2 & 6 & 9 & 7 & 7 & 31 \\
\hline \multirow{2}{*}{ Late Motiv } & Historias & 3 & 6 & 8 & 5 & 0 & 22 \\
& Perfil & 1 & 2 & 1 & 5 & 0 & 9 \\
\hline Las que & Historias & 5 & 0 & 1 & 10 & 20 & 36 \\
Faltaban & Perfil & 3 & 3 & 0 & 0 & 6 & 12 \\
\hline
\end{tabular}

Fuente: Elaboración propia 


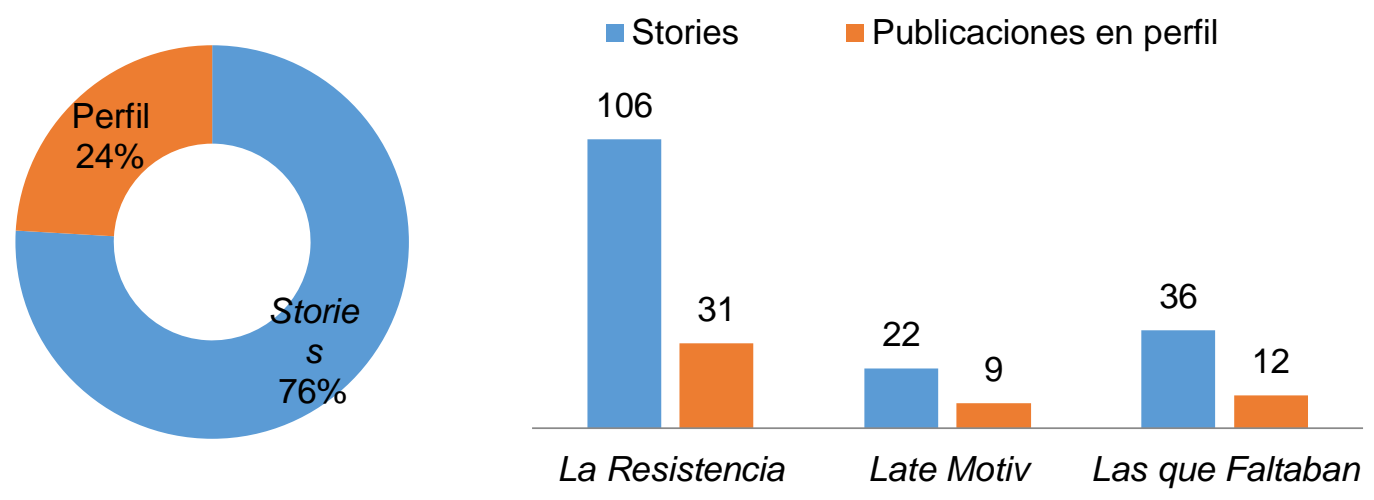

Figura 3. Gráfica de la proporción total de publicaciones en Instagram y por formato Fuente: Elaboración propia

La fotografía es el recurso por excelencia de los contenidos, seguido de los vídeos. Los tres perfiles utilizan estos dos recursos y las promociones, pero solo La Resistencia realiza publicidad de forma ocasional. Además, este formato tiene un modo propio de hacer sus historias sobre los contenidos del programa con mayor interés, gracias a vídeos, retweets de los espectadores, mientras que en su perfil publica partes del programa del presentador, del invitado y de los colaboradores. Late Motiv trabaja con la imagen de Buenafuente quien protagoniza la práctica totalidad de contenidos y con promociones anunciando los próximos invitados, también exponen las partes fundamentales del programa para llegar al público de las redes sociales. En el caso de Las que Faltaban su objetivo es crear expectación ante su emisión semanal, una característica que difiere de los programas diarios, ya que su nivel de contenidos está unido a su día de emisión.

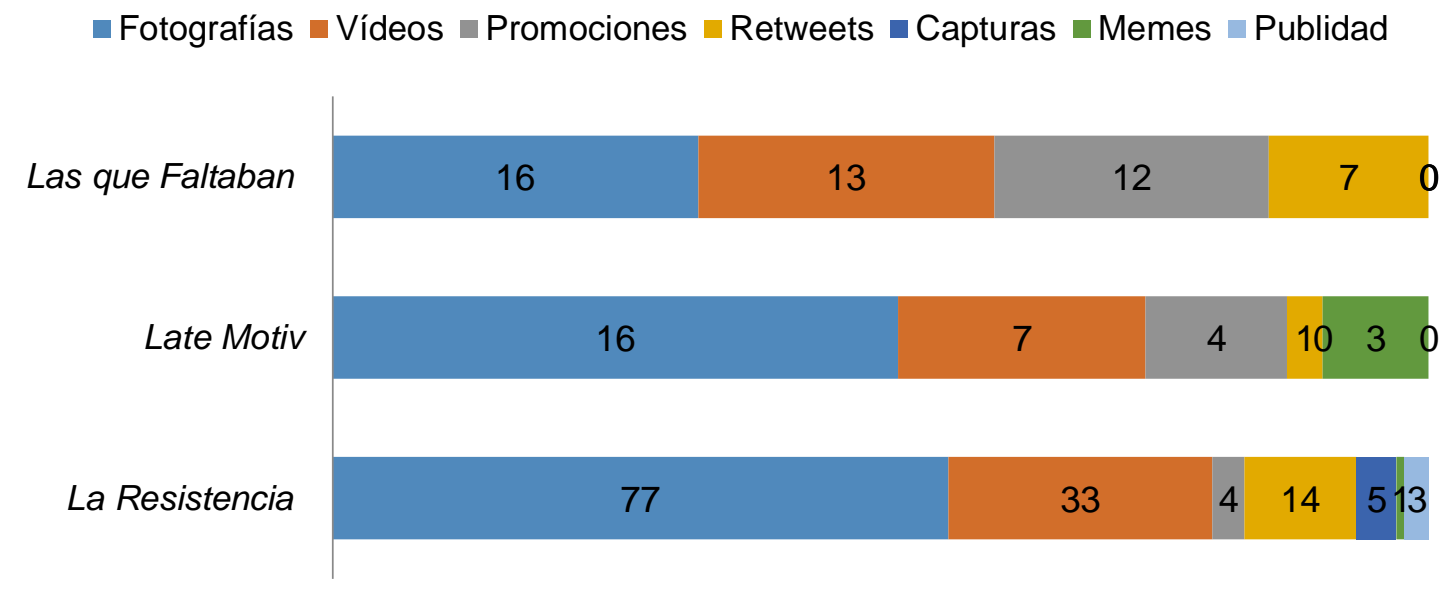

Figura 4. Número y tipo de recursos utilizados en las publicaciones según formato Fuente: Elaboración propia 


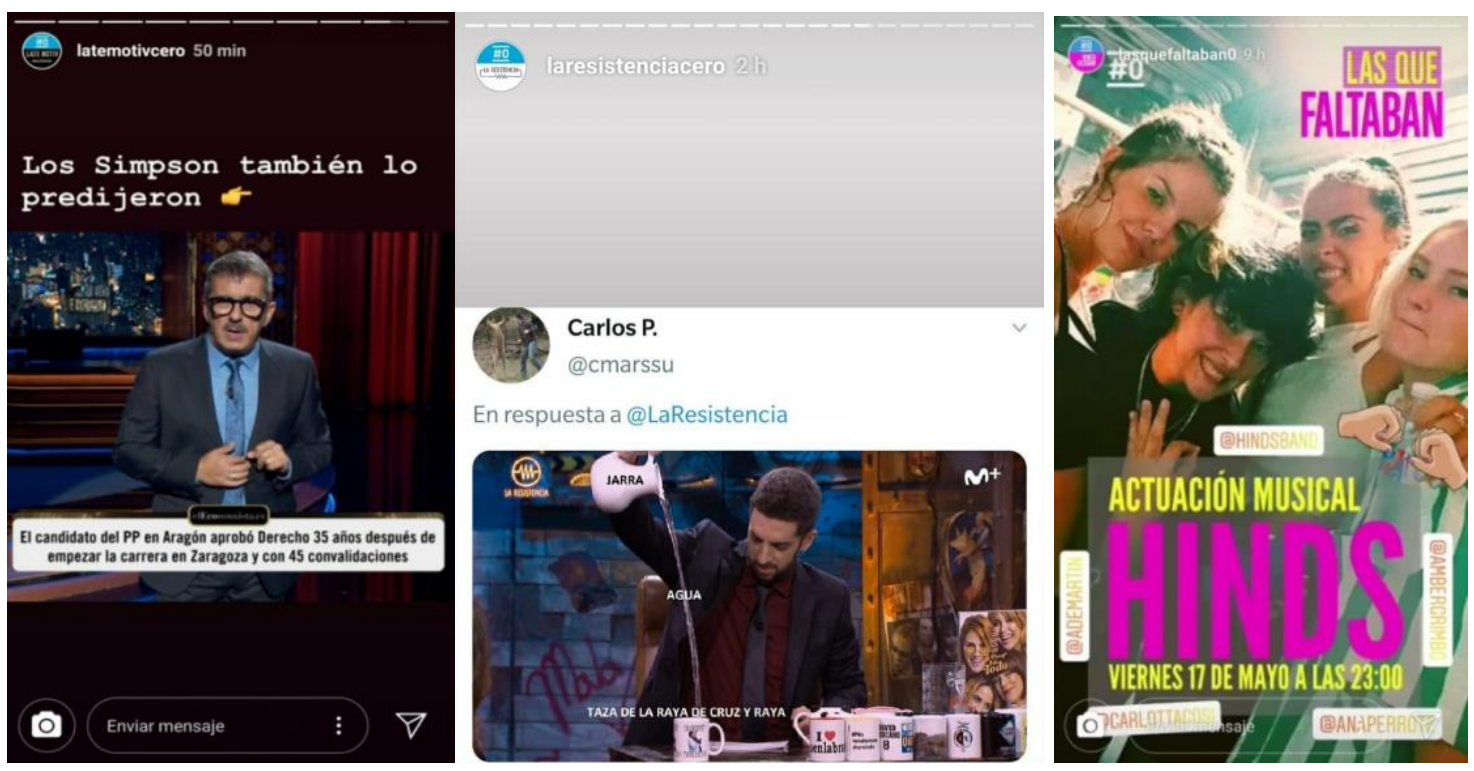

Figura 5. Ejemplo de contenido compartido en historias de Late Motiv, retweet en La Resistencia y promoción en Las que Faltaban

Fuente: Instagram

\section{DISCUSIÓN Y CONCLUSIONES}

Tras el análisis efectuado se comparten las determinaciones de Balboa (2018) en las que apunta que con el nacimiento de \#0 se iniciaba una nueva etapa para el humor, ya que el contenido es un aspecto clave en el nuevo panorama mediático (Medina et al., 2019). Un recurso amparado en la tendencia del infoentretenimiento que la televisión actual ofrece a través de narrativas transmedia en las redes sociales (Lamelo, 2016).

En este sentido, se atestigua como el humor es un recurso que funciona en el panorama televisivo y en sus contenidos desde sus inicios en pantalla, con ejemplos constados en las cadenas generalistas TVE, Antena 3, Telecinco, y en mayor medida en Cuatro y La Sexta, al igual que ocurre desde el canal de pago \#0. Una realidad que ha sido confirmada por el responsable de este contenido en la plataforma de pago más importante de España Movistar+ que, desde el canal \#0, ha sido capaz de reunir a rostros conocidos de la comedia nacional en formatos nuevos, remasterizados y clásicos. Gestados, además, por productoras con amplia experiencia que cuentan para llegar a ese ansiado éxito con margen de mantenimiento en antena mayor que en las cadenas generalistas marcadas por las cifras de audiencia, lo que les permite asentarse en una nueva dieta de consumo de los espectadores que están suscritos a estas plataformas o las consumen desde redes sociales.

Sobre esta idea, se comprueba que los formatos de humor de \#0 exponen sus contenidos de pago, aunque en pequeñas dosis y desde narrativas transmedia, a través de Instagram, como una estrategia de engagement que permite llegar al público 
generalista, al mismo tiempo que ofrece el contenido completo a sus más cuatro millones de suscriptores.

De esta forma, estos resultados podrían centrar nuevas líneas de investigación sobre el uso de Twitter o YouTube y que completasen lo averiguado: que la traslación de contenidos se produce desde una variada y prolija gestión desde Instagram. Así, desde el análisis de tres formatos, se ha constatado que el volumen de publicaciones y la narrativa difiere cada una de las cuentas, las cuales tienen un nivel de seguidores muy dispar entre sí y que se podrían clasificar como un canal de seguimiento y fidelización del formato, en La Resistencia; un modo de exposición viral ligada a la figura de su presentador, Late Motiv; y una ventana de promoción de su emisión para Las que Faltaban.

Por lo tanto, se concluye que el infoentretenimiento es un contenido estratégico para \#0, gracias a una decena de formatos y que este canal se sirve de Instagram y nuevos sistemas narrativos como las historias, cientos como las analizadas, para generar comunidad entre sus millones de suscriptores y compartir sus contenidos en abierto para llegar al público de masas. En definitiva, se evidencia la apuesta de la plataforma por el contenido de humor como elemento diferenciador y determinante para generar productos interesantes con los que atraer público y suscriptores, fundamentalmente, desde el uso transmedia.

\section{Notas}

1 Investigación realizada como personal investigador predoctoral en formación para el período 2018-2022, Departamento de Innovación, Investigación y Universidad del Gobierno de Aragón, cofinanciado con el Programa Operativo Fondo Social Europeo FSE 2014-2020, «Construyendo Europa desde Aragón».

Trabajo realizado bajo el auspicio del Grupo de Investigación en Comunicación e Información Digital (GICID) de la Universidad de Zaragoza, reconocido como grupo de referencia, por el Gobierno de Aragón S29_20R (Núm. 62 Boletín Oficial de Aragón, 26/03/2020), área de Ciencias Sociales, financiado por el Fondo Social Europeo de Desarrollo Regional, FEDER "Construyendo Europa desde Aragón". Instituto Universitario de Investigación y en Patrimonio y Humanidades, Universidad de Zaragoza.

2 Congreso celebrado el 28 y 29 de marzo de 2019 bajo el lema 'Vamos a contar mentiras'. https://tv.uam.es/media/V+Congreso+Nacional+de+Comedia+\%E2\%80\%98Vamos+a+contar+ mentiras\%E2\%80\%99+en+la+UAM/0_fwuh1a8s

3 Actualmente este cómico presenta Last Week Tonight with John Oliver, desde 2016 realiza un repaso semanal de las noticias políticas y de actualidad, aunque comenzó su ascenso a la fama desde que se unió a The Daily Show with Jon Stewart en 2006 como corresponsal. 
4 El 5 de abril de 2019 Movistar+, eliminó un monólogo del cómico Iggy Rubín que realizó en el programa de La Resistencia. La temática del recuso humorístico mencionaba las víctimas de ETA. Tanto la plataforma como la productora emitieron sendos comunicados de prensa al respecto como se recoge en este artículo https://elpais.com/cultura/2019/04/05/television/1554488722_618148.html

${ }_{5}$ Cifras obtenidas de las cuentas oficiales el 20/05/2019 y replicadas en 20/04/2020.

\section{Referencias}

Aguilera, I. C. (2019). La cultura del humor televisivo: el infoentretenimiento español desde su utilidad para las audiencias. Zer, 25(47), 31-50. doi: 10.1387/zer.20705.

Amâncio, M. (2017). "Put it in your Story": Digital Storytelling in Instagram and Snapchat Stories. Universidad de Uppsala, Dominio disciplinario de Humanidades y Ciencias Sociales, Facultad de Ciencias Sociales, Departamento de Informática y Medios.

Antona, T. (2017). El entretenimiento como pilar de la programación televisiva durante el periodo 1958-75. Communication \& Society 30(2), 31-45. doi: 10.15581/003.30.2.31-45

Arroyo, E. (2008). El infotainment. De Caiga Quien Caiga a Noche Hache. En A. Sangro y P. Salgado. (Eds.), El entretenimiento en TV: Guion y creación de formatos de humor (pp.173-192). Barcelona: Laertes.

Balboa, M. (2018). Entre la risa y la ofensa Análisis de la censura como herramienta de control social y evaluación del estado del humor satírico en España. (Trabajo de Fin de Grado de Sociología, Facultad de Economía y Empresa). Universidad de Barcelona.

Berrocal S., Redondo, M. \& Campos-Domínguez, E. (2012). Una aproximación al estudio del infoentretenimiento en Internet: origen, desarrollo y perspectivas futuras. AdComunica. Revista Científica de Estrategias, Tendencias e Innovación en Comunicación. (4), 63-79. http://dx.doi.org/10.6035/2174-0992.2012.4.5

Berrocal, S., Redondo, M., Martín, V., \& Campos-Domínguez, E. (2014). La presencia del infoentretenimiento en los canales generalistas de la TDT Española. Revista Latina de Comunicación Social, 69, 85-103. doi: 10.4185/RLCS-2014-1002

Bourdieu, P. (1996). Sobre la televisión. Barcelona: Anagrama.

Brants, K. (1998). Who's afraid of infotainment? European Journal of Communication, 13(3), 315335.

Buenafuente, A. (Ed). (2011). Lo que vendría a ser la televisión en España según Buenafuente y el Terrat. Barcelona: Editorial Planeta.

Carpio, J. A. (2008). El humor en los medios de comunicación: estudio de Los Guiñoles y sus efectos en las opiniones políticas (Tesis doctoral). Universidad Pontificia de Salamanca. 
Casado, M. (2017). Historias de la Tele. Barcelona: Aguilar.

Casetti, F. y Di Chio, F. (1999). Análisis de la televisión. Instrumentos, métodos y prácticas de investigación. Barcelona: Espasa.

Comisión Nacional de los Mercados y la Competencia. Estadística Trimestral II 2019: Recuperado de http://data.cnmc.es/datagraph/jsp/inf_trim.jsp

Nota de prensa: Un tercio de los hogares pagó por ver contenidos online en 2018: https://bit.ly/2XOKOLG

Contreras, J. M., y Palacio, M. (2003). La programación de televisión. Madrid: Síntesis.

Evans, E. (2011). Trasnmedia Television. Audiences, New Media, and Daily Life. New York: Taylor \& Francis.

Elidrissi, F. (2019, March, 18). El mapa del 'streaming' y la nueva televisión: entre lo local y lo global. The objetive. Recuperado de https://bit.ly/2v5SPj7

Fernández Jiménez, E. (2018). Las imitaciones humorísticas televisivas en España propuesta de clasificación. UNED. Revista de la Asociación Española de Semiótica (Signa), 27, 293322. doi: 10.5944/signa. vol27.2018.19017

Fernández, E. \& Ibáñez, J. L. (1998). Televisión digital y programación: de la televisión de siempre a la televisión de pago y multicanal. Ámbitos. Revista Internacional de Comunicación, 1, 61-71. http://dx.doi.org/10.12795/Ambitos.1998.i01.05

Ferré, C. (Ed). (2013). Infoentretenimiento. El formato imparable de la era del espectáculo. Barcelona: Editorial UOC.

Gabinete de Estudios de la Comunicación Audiovisual. (1999). El anuario de la televisión. Madrid: GECA Consultores.

García-Avilés, J. A. (1999). El pseudoperiodismo satírico, un género creciente en la neotelevisión. Diálogos de la comunicación, (55), 18-29.

García-Avilés, J. A. (2004). Distorsiones de la realidad en la neotelevisión. El pseudoperiodismo satírico y el periodismo de entretenimiento como subgéneros del info-show. En N. Mínguez y N. Villagra. (Eds.). La comunicación nuevos discursos y perspectivas. (pp-3745). Madrid: Colección Comunicación Edipo.

Gascón-Vera, P. (2016): Claves del éxito de una década televisiva: estudios de caso El hormiguero y El intermedio. Revista F@ro, 1 (23), 42-71.

Gascón-Vera, P., \& Marta-Lazo, C. (2019). Análisis del formato Oregón TV, observación participante en un programa periodístico de humor autonómico. En L. Mañas Viniegra y A.M. De Vicente Domínguez. Contenidos audiovisuales, narrativas y alfabetización mediática (pp. 75-87). Madrid: McGraw-Hill. 
Gibbs, G. (2012). El análisis de datos en investigación cualitativa. Madrid: Ediciones Morata.

González-Requena, J. (1989). El espectáculo informativo. O la amenaza de lo real. Madrid: Akal.

Gordillo I. (2009). La hipertelevisión géneros y formatos. Nuevas y viejas tendencias en la televisión del siglo XXI. Quito, Ecuador: Ciespal.

Gordillo, I. (2010). El entretenimiento se contamina de información: Modelos de infoentertainment. En A. Salgado Losada. (Coord.), Creatividad en Televisión. Entretenimiento y Ficción, (pp. 89-109). Madrid: Fragua.

Jenkins, H.; Ford, S. y Green, J. (2013). Spreadable Media. Value, Meaning \& Network Culture. Nueva York, NY: New York University Press.

Krüger, U. M. (1988). Infos- Infotainment- Entertainment? Media Perspektiven, 10, 637-664.

Lamelo, C. (2016). Televisión social y transmedia: nuevos paradigmas de producción y consumo televisivo. Editorial UOC.

Martín, V., \& Berrocal, S. (2017). Innovación y consolidación del «infoentretenimiento» político: una perspectiva histórica. Historia y Comunicación Social, 22(1), 207-219. http://dx.doi.org/10.5209/HICS.55908

Medina, M., Herrero, M., \& Etayo, C. (2015). Impacto de la digitalización en la televisión de pago en España". Revista Latina de Comunicación Social, 70, 252- 69. http://dx.doi.org/10.4185/RLCS-2015-1045

Medina, M., Herrero, M., \& Portilla, I. (2019). La evolución del mercado de la televisión de pago y del perfil de los suscriptores. Revista Latina de Comunicación Social, 1761-1780. http://dx.doi.org/10.4185/RLCS-2019-1409-92

Méndez García de Paredes, E. (2004). Humor y televisión en España. Merlo, P. y Riesgo, B. (eds.): Lhumour hispanique, 147-190. Lyon: Université Lyon II.

Ortells, S. (2009): La mercantilización de la información: la nueva era informativa en televisión. RLCS, Revista Latina de Comunicación Social, (64), 341-353. doi: 10.4185/RLCS-642009-827-341-353

Ortells, S. (2011). La consolidación de los programas de infoentretenimiento en el panorama televisivo español. Fórum de Recerca. (16). Universitat Jaume I.

Prado, E.; Delgado, M.; García Muñoz, N.; Huertas, A.; Larrègola, G. \& Perona, J.J. (1999). El fenómeno Infoshow: la realidad está ahí fuera. Área 5, Revista de Comunicación Audiovisual y Publicitaria, (6), 197-210.

Prado, E. (2003). La espectacularización de la realidad. En Anuario de la Televisión GECA. 178186. Madrid.

Redondo, M., \& Campos-Domínguez, E. (2015). Implicaciones éticas del infoentretenimiento 
televisivo. Comunicació: Revista de Recerca i dÀnàlisi, 32(1), 73-89. doi: $10.2436 / 20.3008 .01 .130$

Salgado, A. (2006). Orígenes y evolución histórica del late night show en Estados Unidos, como principal formato de entretenimiento televisivo. Comunicación y pluralismo, 2, 99-118.

Salgado, A. (2010). Actualidad, humor y entretenimiento en los programas de televisión: de la terminología a la realidad profesional. Trípodos, (27), 59-73.

Sangro, P. (2008). Y yo, ¿de qué me río?, Humor y entretenimiento televisivo. En P. Sangro y A. Salgado. (Eds.), El entretenimiento en TV: Guion y creación de formatos de humor en España (pp. 55-78). Barcelona: Laertes.

Scolari, C. A. (2013). Narrativas transmedia. Cuando todos los medios cuentan. Barcelona: Deusto.

Thussu, D. K. (2007). News as entertainment: The rise of global infotainment. Londres: SAGE.

Torres, J. L. (2019). El auge de las series de ficción españolas y las nuevas narrativas transmedia. La producción original de movistar +: el caso de "la zona". En J. Sierra Sánchez y J. M. Lavín (Ed.), Redes sociales, tecnologías digitales y narrativas interactivas en la sociedad de la información (pp.733-746). Madrid: McGraw-Hill.

Valhondo, J. L. (2007). Infosátira y democratización del espacio televisivo. Quaderns del CAC. Imagen y derecho a la burla, 27, 63-71.

Valhondo, J. L. (2011). Sátira televisiva y democracia en España. La popularización de la información política a través de la sátira. Barcelona: Editorial UOC.

Viciosa, M. (2016, February, 01). Adiós a 26 años de Canal+. Elmundo.es. Recuperado de https://bit.ly/2G8hCoO 